\section{Talking \\ about your achievements}

Lara Isbel

It is not enough to do great work: to progress in your career - you also need to be able to talk about it. Writing CVs, and applying for promotion, funding or other opportunities often require you to describe your achievements and experience. This process can be cringe-worthy (a very Scottish emotion - often referred to as "the Celtic Cringe") and uncomfortable for some people (see Dealing with imposter syndrome). There can be an inner aversion to anything which seems boastful or shameless self-promotion, and also a justifiable nervousness about the 'double bind' (Bateson, 1972) that women in academia often face (see Likeability and the double bind) where likeability and competence are seen as incompatible (Fiske et al., 2002).

While humility certainly goes a long way in a lot of areas in life, there are times when it helps to be able to shine. Describing your accomplishments accurately and positively is important. It is not about selling yourself (or your principles) but demonstrating the impact you have had.

\section{Ingredients}

- Time to reflect.

- Paper or a laptop to make notes.

- Trusted people who can give you constructive feed back.

- Willingness to feel a bit uncomfortable.

\section{Methods}

1. List your achievements. Think back to the roles you have held in the past, or aspects of your current job. What are you most proud of? Write as long a list as you can.

2. Write a short summary of each one. The CAR acronym (Context, Action, Result) is useful for this. Focus on the result section. It's not what you did - it's the difference you made. Think about who benefited from this piece of work, or the wider impact it had. Include that in your summary. Write some keywords for the skills or experience each achievement relates to make it easier to pick out relevant examples.

3. Use positive language. Be bold (while still truthful): 'led', 'delivered', 'achieved' can have more impact than 'helped to', 'tried', 'contributed to', depending on the context. For inspiration, look at how colleagues describe their expertise on their CVs, profile pages or LinkedIn summaries. Don't feel intimated by other people's successes though: behind every glittering super-amazing CV there will be failures too. Jobs or grants that a person didn't get, projects that didn't go according to plan. All you are seeing is a carefully curated snapshot. What phrases or statements stand out or make a strong impression? 


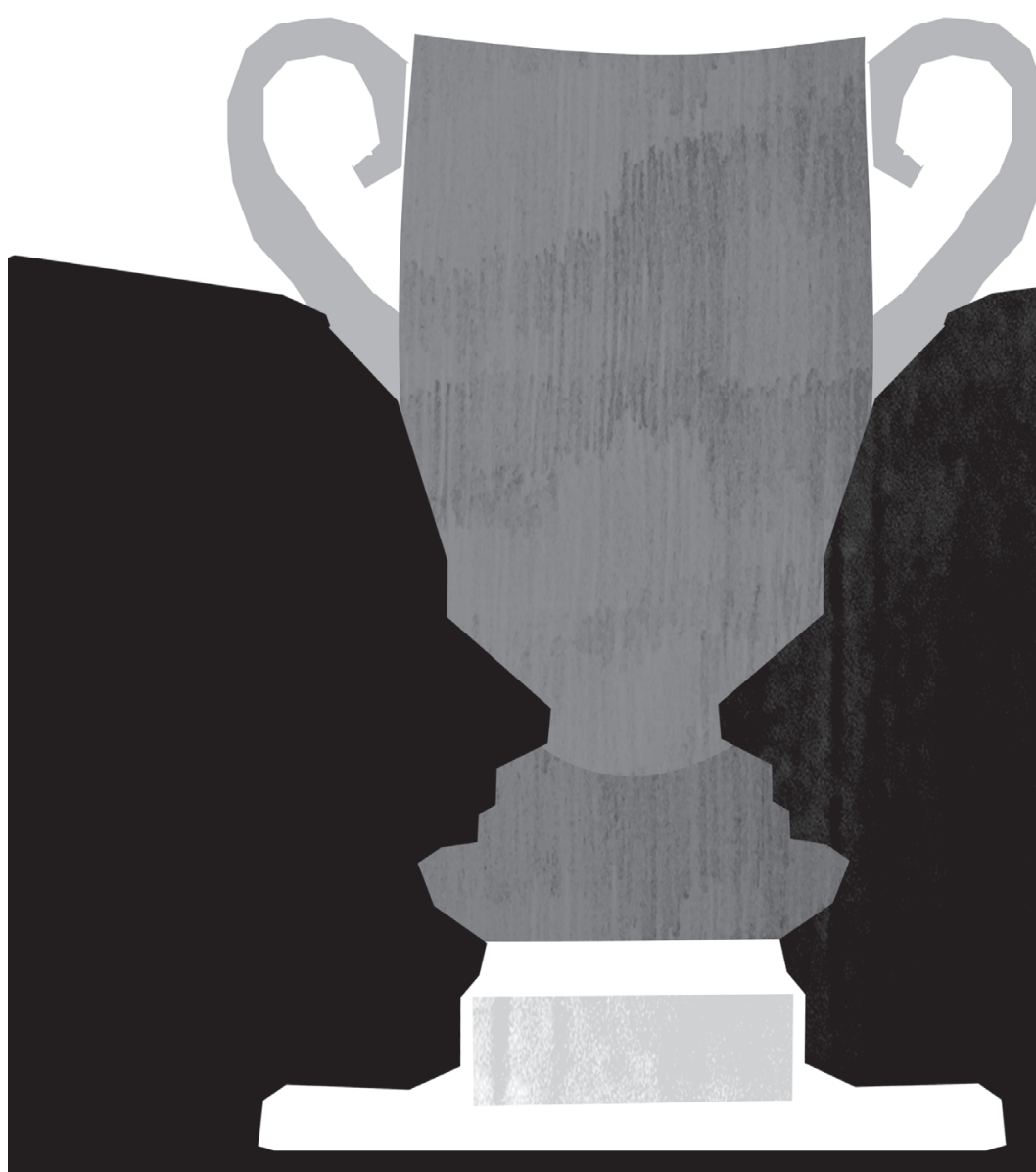

Experiment with the language you use to describe your achievements.

4. Select relevant examples. Pay close attention to what you need to demonstrate to be successful for the job or funding opportunity etc. and choose the most important, relevant examples. Less is often more; you don't need to list everything you've ever achieved in your whole career.

5. Get feedback from trusted people. Peers and mentors can be useful for this. It is often much easier to see someone else's strengths than your own. If you can, try to get feedback from people who have a lot of experience in recruitment or sit on promotion panels or grant funding schemes. They could help you by reviewing applications you have written or giving you a mock interview. If you feel your application or interview response is accurate but peers, mentors or colleagues tell you that you are downplaying your experience, trust them. Experiment some more with the language. Don't be discouraged if it feels a bit uncomfortable - it's a new approach so it is likely to be unfamiliar. 
6. Practise saying it out loud. As well as writing short concise statements, preparing short pitches about your expertise can stand you in good stead. This could be for a job interview, but also networking at events. If there is an area you are keen to get more experience in, having a good, brief story about your interests can open doors. Saying it out loud over and over again, (this could be when driving the car or washing the dishes), helps embed it until it sounds easy and natural.

7. Celebrate success. Recognising the difference you made after the time and effort you put in can make your job more rewarding, and also make things feel more like 'real' accomplishments. Championing others, particularly junior colleagues and noticing their achievements can support a positive working environment. When accomplishments are celebrated as a matter of course, writing or talking about them becomes less cringe-worthy and more of a natural reflection of the progress you've made because of the time, energy, care and effort you put into your work. 